\title{
Evaluation of amniotic fluid volume among Sudanese diabetic patients in third trimester using ultrasound
}

\author{
Elsafi Ahmed Abdalla ${ }^{1}$, Caroline Edward Ayad ${ }^{1, ~}{ }^{*}$, Rian Omer Massaad Elbasheer ${ }^{2}$, Amel Gadal $^{1}$ \\ ${ }^{1}$ Radiology and Ultrasound Department, College of Medical Radiological Science, Sudan University of Science and Technology, \\ Khartoum, Sudan \\ ${ }^{2}$ Radiology Department, Khartoum Hospital, Khartoum, Sudan
}

Email address:

dr.elsafi@gmail.com (E. A. Abdalla), carolineayad@yahoo.com(C. E. Ayad),RaianOmer@yahoo.com (R. O. M. Elbasheer), amelgadal@yahoo.com(A.Gadal)

\section{To cite this article:}

Elsafi Ahmed Abdalla, Caroline Edward Ayad, Rian Omer Massaad Elbasheer, Amel Gadal. Evaluation of Amniotic Fluid Volume among Sudanese Diabetic Patients in Third Trimester Using Ultrasound. International Journal of Medical Imaging.

Vol. 1, No. 2, 2013, pp. 26-31. doi: 10.11648/j.ijmi.20130102.13

\begin{abstract}
Assessment of amniotic fluid volume in diabetic pregnancies is important for maternal and fetus health judgment and pregnancy outcome and for this reason the purpose of this study is relevant using two ultrasonographic methods. The study included 49 Sudanese pregnant women with diabetes mellitus and 20 subjects as control group .The study was conducted at Omdurman Military hospital and Al -Saudi hospital in the period from December 2011 to April 2012. Ultrasound was done by using Mindray 6600, 2200 ultrasound machine fitted with $3.5 \mathrm{MHZ}$ convex probe. Amniotic fluid volume (AFV) was measured by largest pocket and Amniotic fluid index (AFI).The mean AFI for control group was found to be (16.6 \pm 2.4$)$ and the largest pocket was $(6.6 \pm 0.7)$, for diabetic sample AFI was (20.3 \pm 5.6$)$, largest pocket was (7.4 \pm 1.9$)$.T-test showed that AFI was found to be 4.66 at $\mathrm{p}<0.001$, largest pocket was 2.93 at $p$-value 0.005 . There is significant difference between AFI measurements and largest pocket for diabetic pregnant ladies compared to the control group.Measurements of AFV using ultrasound compared with type of diabetic and diabetic status is of great value to categorize the relative risk of complications related to diabetes.
\end{abstract}

Keywords: Diabetes, Amniotic Fluid Volume, Ultrasound

\section{Introduction}

Measuring amniotic fluid volume is essential in pregnancy assessment. [1]Changes in amniotic fluid volume are associated with adverse pregnancy outcome. The estimation of amniotic fluid volume in the late pregnancy is important for the assessment of fetus health, death, operative delivery.[1 ]

The amniotic fluid index (AFI) and single deepest pocket are used to detect oligohydramnios in order to predict risk for caesarean delivery. [2] Findings of diminished amniotic fluid index is generally perceived as a sign of placental in sufficiency [3] ,Intra Uterine Growth Retardation as well as renal anomalies in the second trimester.[1]

The most common reasons of Polyhydramnios are increased urine production and maternal diabetes mellitus, fetal macrosomia or other conditions that predispose to a fetal hyperdynamic circulation. [4]

Several studies on AFI has demonstrated serial changes of mean AFI values weekly with the threshold for oligohydromnios and polyhydromnios during pregnancy.[ $5,6,7]$

Normally the amniotic fluid volume increases from approximately $250 \mathrm{~mL}$ at 16 weeks to $1000 \mathrm{~mL}$ at 34 weeks, declining thereafter to approximately $800 \mathrm{~mL}$ at term. The amniotic fluid volume reflects the status of both the mother and the fetus and is altered in many physiological and pathological conditions. [4]

Both pre gestational [8] and gestational diabetes mellitus $[9,10]$ can lead to fetal death, or fetal abnormalities .[11,12,13]

A Varity of approach including biophysical methods, deepest pocket, AFI, 3D, subjective estimation is important and the clinician should consider also AFV as an assessment technique for a given clinical situation taking into account the biology of amniotic fluid formation and regulation through gestation.

Evaluation of amniotic fluid volume using 
ultrasonography is of great value [14] in obstetrics care and it has become an integral and important component of pregnancy assessment therefore this study used the ultrasound as an imaging method for this evaluation.

\section{Objectives}

This study aimed to evaluate the amniotic fluid volume by 2 methods as Amniotic fluid Index (AFI) and single deepest/largest pocket in different diabetes status for Sudanese population using ultrasound so as to evaluate the volume measurements when using these 2 methods as well as to evaluate the amniotic fluid volume in normal and diabetes patients.

\section{Materials \&Methods}

This study was conducted at two of Khartoum hospitals, including AlSaudi hospital, Omdurman Military Hospital. Data were collected in the period from December 2011 to May 2012.Ultrasound devices with a good resolution including Mindray 6600 with TA probe $3.5 \mathrm{MHZ}$ and Mindray 2200 -DP with TA probe 3.5 MHZ were used.

The study included 49 diabetic pregnant ladies in third trimester, 20 normal subjects were selected as control group .There is no patient identification or details were published .

Patients were positioned in supine, coupling agent (gel) was applied to lower abdomen; the amniotic volume had been measured using the following methods:

In the Single deepest pool/largest pocket: The size of the deepest, cord-free pool of amniotic fluid is assessed with the ultrasound probe perpendicular to the maternal abdomen . The vertical depth of the largest pool is measured. 1-cm pool was considered acceptable in normal pregnancy.

Amniotic fluid index: Using the maternal umbilicus as a reference point, the abdomen is divided into four quarters. With the ultrasound probe held in the longitudinal axis of the mother and perpendicular to the floor, the largest vertical pool depth in each quadrant is recorded. The sum of these measurements represents the amniotic fluid index (AFI), an AFI $<5 \mathrm{~cm}$ is classified as oligohydramnios and an AFI $>25$ $\mathrm{cm}$ is classified as polyhydramnios.

\section{Data Analyses Procedures}

The data were analyzed using SPSS program version16 independent T- test, correlation analysis according to Petrie and Watson (2006), simple tables including frequency and percentages, cross tabulations were used for the variables and $p$-value for testing the results significances of the variables was used, $P$ value is significant when $<0.001$.

\section{Results}

Tables from 1 to 5 presented the patients demographic data, age, diabetes status, patient's history, type of diabetes and Ultrasound findings.

Table (1): Diabetic pregnant patient's age classes, frequencies and percentage

\begin{tabular}{lll}
\hline Age Classes & Frequency & Percentage\% \\
\hline $15-19$ & 6 & 12.2 \\
$20-24$ & 12 & 24.5 \\
$25-29$ & 9 & 18.4 \\
$30-34$ & 12 & 24.5 \\
$35-39$ & 6 & 12.2 \\
$40-44$ & 4 & 8.2 \\
Total & 49 & 100.0 \\
\hline
\end{tabular}

Table (2): diabetic status, frequencies and percentage

\begin{tabular}{lll}
\hline Diabetic status & Frequency & Percentage\% \\
Controlled & 35 & 71.4 \\
Un-controlled & 14 & 28.6 \\
Total & 49 & 100.0 \\
\hline
\end{tabular}

Table (3): history of polyhydramnios and oligohydromonious , frequencies and percentage.

\begin{tabular}{llllll}
\hline $\begin{array}{l}\text { History of } \\
\text { Polyhydr } \\
\text { amnios }\end{array}$ & $\begin{array}{l}\text { Frequ } \\
\text { ency }\end{array}$ & $\begin{array}{l}\text { Percenta } \\
\text { ge\% }\end{array}$ & $\begin{array}{l}\text { History of } \\
\text { Oligohydra } \\
\text { mnios }\end{array}$ & $\begin{array}{l}\text { Freque } \\
\text { ncy }\end{array}$ & $\begin{array}{l}\text { Percent } \\
\text { age\% }\end{array}$ \\
No & 41 & 83.7 & No & 44 & 89.8 \\
Yes & 8 & 16.3 & Yes & 5 & 10.2 \\
Total & 49 & 100.0 & Total & 49 & 100.0 \\
\hline
\end{tabular}

Table (4): Frequencies and percentage of US findings in diabetic pregnant patients.

\begin{tabular}{lll}
\hline Us findings & Frequency & Percentage \\
\hline Normal & 36 & 73.5 \\
Polyhydramnios & 13 & 26.5 \\
Total & 49 & 100.0 \\
\hline
\end{tabular}

Table (5): type of diabetic, frequencies and percentages

\begin{tabular}{lll}
\hline Types of diabetic & Frequency & Percentage\% \\
\hline Gestational diabetes & 12 & 24.5 \\
Type I & 19 & 38.8 \\
Type II & 18 & 36.7 \\
Total & 49 & 100.0 \\
\hline
\end{tabular}


Elsafi Ahmed Abdalla et al.: Evaluation of Amniotic Fluid Volume among Sudanese Diabetic Patients in Third Trimester Using Ultrasound

Table (6): frequencies and percentage demonstrate of Amniotic fluid Index AFI and largest pocket

\begin{tabular}{llllll}
\hline AFI & Frequency & Percentage\% & Largest pocket(cm) & Frequency & Percentage \% \\
\hline $5-25$ & 36 & 73.5 & $3-8$ & 36 & 73.5 \\
$>25$ & 13 & 26.5 & $>8$ & 13 & 26.5 \\
Total & 49 & 100.0 & Total & 49 & 100.0 \\
\hline
\end{tabular}

Table (7): cross tabulation between diabetic status and US findings for diabetic pregnant patients.

\begin{tabular}{|c|c|c|c|c|}
\hline & & $\begin{array}{l}\text { Us findin } \\
\text { Normal }\end{array}$ & Polyhydramnios & Total \\
\hline \multirow{2}{*}{ Diabetic status } & Control & 25 & 10 & 35 \\
\hline & Uncontrolled & 11 & 3 & 14 \\
\hline Total & & 36 & 13 & 49 \\
\hline \multirow{2}{*}{ History of Polyhydramnios } & No & 31 & 10 & 41 \\
\hline & Yes & 5 & 3 & 8 \\
\hline Total & & 36 & 13 & 49 \\
\hline \multirow{2}{*}{ History of Oligohydramnios } & No & 33 & 11 & 44 \\
\hline & Yes & 3 & 2 & 5 \\
\hline Total & & 36 & 13 & 49 \\
\hline
\end{tabular}

Table (8): cross tabulation between the type of diabetic and US findings for diabetic pregnant patients.

\begin{tabular}{|c|c|c|c|c|}
\hline & & $\begin{array}{l}\text { US findir } \\
\text { Normal }\end{array}$ & Polyhydramnios & Total \\
\hline \multirow{3}{*}{$\begin{array}{l}\text { Type of } \\
\text { Diabetic }\end{array}$} & Gestational Diabetes & 5 & 7 & 12 \\
\hline & Type I & 15 & 4 & 19 \\
\hline & Type II & 16 & 2 & 18 \\
\hline Total & & 36 & 13 & 49 \\
\hline
\end{tabular}

Table (9): Cross tabulation between the AFI, Largest pocket and US findings for diabetic pregnant patients.

\begin{tabular}{|c|c|c|c|c|}
\hline & & $\begin{array}{l}\text { US find } \\
\text { Normal }\end{array}$ & Polyhydramnios & Total \\
\hline \multirow{2}{*}{ AFI } & $5-25$ & 36 & 0 & 36 \\
\hline & $>25$ & 0 & 13 & 13 \\
\hline Total & & 36 & 13 & 49 \\
\hline \multirow{2}{*}{ Largest pocket } & $3-8$ & 36 & 0 & 36 \\
\hline & $>8$ & 0 & 13 & 13 \\
\hline Total & & 36 & 13 & 49 \\
\hline
\end{tabular}

Table (10): Demonstrates diabetic status versus type of diabetic of diabetic pregnant patients.

\begin{tabular}{llllll}
\hline & Type of diabetic & & & Total \\
& & Gestational diabetes & Type I & Type II & 35 \\
\hline \multirow{2}{*}{ Diabetic status } & Controlled & 9 & 13 & 13 & 14 \\
Total & Un-controlled & 3 & 6 & 5 & 49 \\
\hline
\end{tabular}


Table (11): Demonstrates of history of oligohydramnios, Polyhydramnios ,AFI, Largest pocket versus types of diabetic

\begin{tabular}{|c|c|c|c|c|c|}
\hline & & $\begin{array}{l}\text { Type of diabetic } \\
\text { Gestation Diabetes }\end{array}$ & Type I & Type II & Total \\
\hline \multirow{2}{*}{ History of Oligo hydramnios } & NO & 11 & 15 & 18 & 44 \\
\hline & Yes & 1 & 4 & 0 & 5 \\
\hline Total & & 12 & 19 & 18 & 49 \\
\hline \multirow{2}{*}{ History of Poly hydramnios } & NO & 10 & 17 & 14 & 41 \\
\hline & Yes & 2 & 2 & 4 & 8 \\
\hline Total & & 12 & 19 & 18 & 49 \\
\hline \multirow{2}{*}{ AFI } & $5-25$ & 4 & 15 & 17 & 36 \\
\hline & $>25$ & 8 & 4 & 1 & 13 \\
\hline Total & & 12 & 19 & 18 & 49 \\
\hline \multirow{2}{*}{ Largest pocket } & $3-8$ & 4 & 15 & 17 & 36 \\
\hline & $>8$ & 8 & 4 & 1 & 13 \\
\hline Total & & 12 & 19 & 18 & 49 \\
\hline
\end{tabular}

Table (12): Demonstrates of age classes versus type of diabetic for diabetic pregnant patients.

\begin{tabular}{cccccc}
\hline & & \multicolumn{2}{c}{ Type of diabetic } & & Total \\
& & Gestational Diabetes & Type I & Type II & 6 \\
\multirow{4}{*}{ Age } & $15-19$ & 3 & 1 & 2 & 12 \\
& $20-24$ & 1 & 7 & 2 & 9 \\
& $25-29$ & 4 & 5 & 3 & 12 \\
& $30-34$ & 3 & 2 & 4 & 6 \\
& $35-39$ & 0 & 2 & 1 & 4 \\
& $40-44$ & 1 & 19 & 18 & 49 \\
\hline
\end{tabular}

Table (13): demonstrates of significant of test.

\begin{tabular}{lll}
\hline \multicolumn{1}{l}{-Test } & AFI & Largest Pocket \\
\hline Mean \pm SD Control & $16.6 \pm 2.4$ & $6.6 \pm 0.7$ \\
Mean \pm SD Test & $20.3 \pm 5.6$ & $7.4 \pm 1.9$ \\
$T$ & 4.66 & 2.93 \\
$P$ & $<0.001$ & 0.005 \\
\hline
\end{tabular}

\section{Discussion}

There are many different methods to evaluate and measure the amniotic fluid but all of these methods are difficult, ultrasonic measurements are currently used to evaluate amniotic fluid volume. The ultrasonic methods which are used to measure amniotic fluid volume are Amniotic Fluid Index (AFI)[15] Largest Vertical Pocket (LVP) measurement[16], Two diameter pocket measurement, Largest Transverse Pocket (LTP)maximum transverse[17].

In our study AFI and largest pocket were used to evaluate amniotic fluid volume the commonest AFI index ranged between $5-25$ acts (73.5\%), and who is greater than $>25$ acts $(26.5 \%)$. The commonest largest pocket in 3-8 was $(73.5 \%),>8(26.5 \%)$ as presented in table (6)

Our study showed that there is a relationship between diabetic status, history of polyhydramnios, ligohydramnios, type of diabetes, AFI and largest pocket in ultrasound examinations as seen in table( 4$)$.

The controlled diabetes resulted in 10 patients affected with poly hydramnios while 25 out of 36 patients were not affected. Uncontrolled diabetes resulted in 11 patients with no poly hydramnios and 3 patients were affected with poly hydramnios .

Table (7) reflects that patient's history of polyhydramnios or oligo hydromonus correlated to ultrasound findings as normal or affected with poly hydramonus were detected in some subjects of the selected sample.

Gestational diabetes is associated with many complications during pregnancy as fetal hyper insulinaemia[19]. Poor maternal glucose control, can lead to this complications as it related to interaction between maternal and fetal circulations, diabetic can increase glucose 
concentrations, amino acids and fats, and hyper insulinemia and could affect a number of nutrient transport and metabolic pathways [18].

The diabetes type has been evaluated and was presented in table (8), in patients with G.D; 7 patients out of 12 patients are with poly hydramnios, in type $1 ; 4$ out of 19 patients were poly hydramnios, In Type 2; 2 out of 18 is poly hydramnios. In controlled diabetic the G.D were in 9 patients, type1 (13 patients), type 2 (13 out of 35 patients).

Uncontrolled diabetic the G.D were in 3 patients, type1 (6 patients), type 2 (5 patients out of 14.) as seen in table (10)

AFI in (5-25ml) normal was (36 patients), none were polyhydramnios, patients $>25 \mathrm{ml}$ all were polyhydramnios (13 patients).The largest pocket $(3-8 \mathrm{ml})$ normal (36 patients), none were polyhdramnios, patients $>8 \mathrm{ml}$ average were polyhdramnios (13 patients) this was presented in table (9)

Patients with history of oligohydramnios or polyhydramnios correlated to diabetic type had also been evaluated in table(11).AFI $5-25 \mathrm{ml}$ the largest affected patients in type 2 (17 patients), type1 (15 patients), G.D (4 patients) from 36 patient.$>25 \mathrm{ml}$ largest in G.D is (8 patients), type 1 ( 4 patients), type 2 is one patients from 13 patients. In the evaluation using the largest pocket 3-8 $\mathrm{ml}$ more affected in type 2 is (17 patients), then type 1 is ( 15 patients), then G.D (4 patients) from 36 patients. $>8 \mathrm{ml}$ largest is G.D ( 8 patients), type1 (4 patients), type 2 is one patients from 13 patients.

Varma et al had discussed the production and regulation of amniotic fluid ;he mentioned that it is a dynamic and complex process involving mainly fetal urine output, fetal swallowing, and fetal lung fluid flow and the amniotic fluid volume is related to fetal weight, but the mechanism of this observation is not understood [19].

Three different theories have been introduced to explain the possible interaction between maternal glycemic status and amniotic fluid volume: maternal hyperglycemia induces fetal hyperglycemia resulting in osmotic dieresis, when the fetal threshold for glucose is exceeded; as glucose equilibrates across the placenta there is an isosmotic movement of fluid towards the fetal compartment with volume expansion and an increase in glomerular filtration rate leading to enhanced fetal urine output production; and decreased fetal swallowing without[20].

Comments affected ages were presented in table(12) as the most affected ages were 20-24 and ages from 30to 34 all were of diabetes type 1 .

The mean \pm SD for control group for AFI was found to be (16.6 \pm 2.4$)$ and the largest pocket was $(6.6 \pm 0.7)$.The mean \pm SD for diabetic sample for AFI was (20.3 \pm 5.6$)$, largest pocket was (7.4 \pm 1.9 ).T-test for the AFI was found to be 4.66 at $\mathrm{p}<0.001$, largest pocket was $2.93 \mathrm{p}$-value 0.005 . There is significant correlation between AFI measurements and single largest pocket as seen in table (13)Using the AFI and largest pocket technique is an excellent method in evaluating the amniotic fluid volume [21]. Its validity has been demonstrated by Moore and Cayle[5] as well as other authors[22].

\section{Limitations}

Our study is hampered by one limitation that the sample size is small.

\section{Conclusion}

This study deals mainly with diabetic pregnancies to measure AFV. AFV can be obtained significantly by two methods of measurements including AFI and largest pocket.

Ultrasonography (US) has been widely accepted as a screening procedure in measurements of AFV in diabetic pregnancy. It is quick, available, non invasive imaging modality. In addition, no preparation is needed and no presence of ionizing radiation, so it is a safer diagnostic method.

US can define the change of amniotic fluid. As the normal values are known it can detect any changes due to diabetes. Measurements of AFV are an important parameter to show and categorize relative risk of morbidity due to diabetes effects .

\section{References}

[1] DB Schrimmer, TR Moore.Sonographic Evolution of Amniotic Fluid Volume. Clin Obstet Gynaecol 2002;45:1026-38

[2] E Murray et al..Assessment of foetal growth size and well being. A guide to effective care in pregnancy and child birth. 3rd ed. Oxford university press $2000 ; 80-92$.

[3] Desai pan kay et al.Decrease of amniotic fluid index in low risk pregnancy. Any significance? J obstet Gynecol Ind; 2004; 54(5) $464-466$.

[4] Trish Chudleigh, basky thilaganthan. obstetric ultrasound (how why and when), third edition, endburgh London New York, 2004;page 14

[5] TR Moore, JE Cayle..The AFI in normal human pregnancy. Am J Obstet Gynaecol; 1990; 162:1168-73.

[6] EC Nwosu, CR Welch PR Manasse..Longitudional assessment of amniotic fluid index. Br J Obstet Gynaecol; 1993; 100:816-9.

[7] M Hallak, B Kirshan, EO Smith, DV Cotton.Amniotic fluid index; gestational age specific values for normal human pregnancy. J Reprod Med; 1993; 38:853-5.

[8] JL Kitzmiller. Sweet success with diabetes. The development of insulin therapy and glycaemic control for pregnancy. Diabetes Care 16[Suppl 3]1993:107-121

[9] DR Coustan. Gestational diabetes. Diabetes Care 16[Suppl 3]: $1993 ; 8-15$.

[10] BM Casey, MJ Lucas, DD McIntire, Leveno KJ Pregnancy outcomes in women with gestational diabetes compared with the general obstetric population. Obstet Gynecol 1997;90: 869-873.

[11] L Cordero, MB Landon ..Infant of the diabetic mother .Clin 
Perinatol 1993;20: 635-647

[12] M Hod, Merlob, S Friedman, A Schoenfeld, J Ovadia.Gestational $\mathrm{P}$ diabetes mellitus. A survey of perinatal complications in the 1980 s. Diabetes 40[Suppl 2] $1991 ; 74-78$

[13] SS Khwaja, SA Uduman, H Al-Sibai, SA Al-Suleiman .The oversized infant. A study of 86 cases. Aust NZ J Obstet Gynaecol 1986;26: 22-25

[14] HF Ever et al. Comparability of the amniotic fluid index and single deepest pocket measurements in clinical practice. Aus and NJ J of obstet Gynecol 2003;43: 75-77

[15] JP Phelon, M Ahn, CU Smith, SE Rutherford.Amniotic fluid index in normal human pregnancies. Report Med 1987; $32: 601-4$.

[16] EF Magann, TE Nolan, LW Hess, RW Martin, NS Whitworth, JC Morrison. Measurement of amniotic fluid volume; accuracy of ultrasound techniques. Am J Obstet Gynaecol; 1992,167:1363

[17] D Gramellini, L Delle Chiaie, G Piantelli, L Sansebastiano, S
Fieni, E Vadora..Sonographic assessment of amniotic fluid volume between 11 and 24 weeks of gestation: construction of reference intervals related to gestational age. Ultrasound Obstet Gynecol 2002; 17:410-5.

[18] DTD Osmond, C J Nolan, RG King, S.P Brennecke, NM Gude. Effects of gestational diabetes on human placental glucose uptake, transfer, and utilization Diabetologia 2000;43: 576-582

[19] TR Varma, S Bateman, RH Patel, G.V.P Chamberlain, U. Pillai. Ultrasound evaluation of amniotic fluid: outcome of pregnancies with severe oligohydramnios Department of Obstetrics and Gynaecology1987.

[20] L Sandra hagen .Asert textbook of diagnostic ultrasonography, fourth edition, 1995.

[21] JP Phelan, MO Ahn, CVSmith, S.E Rutherford, E. Anderson. Amniotic Fluid Index measurements during pregnancy, $J$ Reprod Med 1987;32(8), 601- 604

[22] RJ Hernandez-Herrera, M Ochoa-Torres, D. Salazar-Garcia, B. Solis-Estrada .Amniotic Fluid Index Accuracy in Mid-Trimester, Fetal Diagn Ther 2009;26(1), 6-9. 